\title{
Designing and developing a web tool to support Strategic Environmental Assessment
}

\author{
Dr Ainhoa González ${ }^{\mathrm{a}, *}$, Justin Gleeson ${ }^{\mathrm{b}}$, Eoghan McCarthy ${ }^{\mathrm{b}}$ \\ ${ }^{a}$ School of Geography, Newman Building, University College Dublin, Dublin 4, Ireland \\ ${ }^{\mathrm{b}}$ All-Island Research Observatory, Maynooth University Maynooth, Ireland
}

\section{A R T I C L E I N F O}

\section{Keywords:}

Impact assessment

Geographic information systems

Online geoprocessing

Decision support tool

Multi-criteria assessment

\begin{abstract}
A B S T R A C T
Strategic Environmental Assessment (SEA) requires taking into account the sensitivity of the area likely to be affected when identifying and characterising potential impacts resulting from plans and programmes. This entails consideration of the intrinsic characteristics that make the area susceptible to change, and incorporation of stakeholder values and concerns. A geospatial approach to these considerations facilitates identification of potential land-use conflicts and better informs planning decisions.

Building on online geoprocessing advancements, we have developed an Environmental Sensitivity Mapping web tool containing novel functionality to support SEA. This paper presents the methodological framework for its participative multi-criteria approach and its architecture, and describes its functionality simulating a practical application. The web tool has the potential to break down data access and specialised skills barriers while providing a means for enhancing SEA consistency and transparency. However, data limitations remain affecting its applicability, and further technological advancements may help enhance its functionality.
\end{abstract}

\section{Introduction}

Strategic planning provides a vision for future sectoral development interventions in a region. A sustainable approach to planning requires that planners and decision-makers not only understand patterns of socio-economic growth and associated development needs, but also the intrinsic susceptibility of environmental receptors, and of the receiving environment as a whole. This knowledge base is a pre-requisite to direct developments towards least vulnerable or sensitive locations in order to avoid of reduce environmental impacts and promote sustainable development. Assessing and mitigating impacts is a mandatory requirement under the European Strategic Environmental Assessment (SEA) and Environmental Impact Assessment (EIA) Directives (EC, 2001, 2014) - procedures that are also applied in other countries worldwide (Dalal-Clayton and Sadler, 2005; Wood, 2013). SEA and EIA require that the effects of development plans/programmes and projects, respectively, are assessed in order to identify and mitigate any significant adverse impacts on population and human health, biodiversity, flora, fauna, water, air, climate, soils, geology, landscape, cultural heritage and material assets (EC, 2001, 2014).

The SEA Directive specifically refers to the vulnerability of the area likely to be affected when identifying and characterising potential impacts (EC, 2001, Annex II, 2), and the EIA Directive warns about the potential for significant effects when proposing developments in environmentally sensitive locations (EC, 2014, article 28). Therefore, identification of vulnerable or sensitive areas can provide an objective critical foundation to support evidence-based assessments to minimise potentially incompatible land-uses and unsustainable developments (Kværner et al., 2006; González, 2017a). In impact assessment, the terms vulnerability and sensitivity are often interchangeably used to refer to susceptible biophysical features (e.g. water resources or habitats of community interest) that could be significantly affected as a result of human intervention (e.g. plan/programme/project implementation). In the context of this paper, environmental sensitivity is adopted from here on for simplicity and clarity.

Although planners are equipped with innate spatial thinking, and natural resource distribution and protection are intrinsically geographical issues, there is often poor integration of scientific environmental considerations into planning practice (Jay et al., 2007; Runhaar and Driessen, 2007). This also includes having due regard to the intrinsic sensitivity of the environment. The role that good sciencepractice communication plays on facilitating this integration, and ultimately on contributing to SEA/EIA impact on planning and decisionmaking, is demonstrated in the literature (e.g. Aschemann, 2004; Cartwright et al., 2016; Michielsen et al., 2016; Vicente and Partidário, 2006; Wieland and Gutzler, 2014). The World Wide Web coupled with

\footnotetext{
${ }^{*}$ Corresponding author.

E-mail addresses: ainhoa.gonzalez@ucd.ie (D.A. González), justin.gleeson@mu.ie (J. Gleeson), eoghan.mccarthy@mu.ie (E. McCarthy).
} 


\section{Software availability}

Name of software Environmental Sensitivity Mapping (ESM) web tool

Developers Justin Gleeson, Eoin McCarthy

Contact email ainhoa.gonzalez@ucd.ie (corresponding author)

Contact address School of Geography, University College Dublin, Belfield, Dublin 4, Ireland

Hardware required PC with Windows operating system, and two servers - one for data preparation and one for web tool deployment

Software required for development ArcGIS 10.5, ArcGIS Online (AGOL), ArcGIS Web AppBuilder (Developer Edition),
ArcGIS API for Javascript, ArcGIS for Server

Software required for use Internet browser (tested on Firefox, Chrome, Edge and Internet Explorer)

Programming language JavaScript, HTML

Form of data repository Geodatabases. All data are publicly available

URL of web tool http://airomaps.nuim.ie/id/ESM

Availability Data preparation and technical web tool development details available at https://drive.google.com/file/d/ 12oIGlAoRyvv6fKo6Rhz3e2s-qqpGmMpe/view?usp = sharing

First available 2017 advanced online Geographic Information Systems (GIS) has opened public access to geospatial data in previously unthinkable ways. E-visualisation and e-sharing initiatives for open data are enhancing science-practice communication and, ultimately, transparency, objectivity and accountability of decisions (González and Gazzola, 2011; Kitchin, 2014; Mourhir et al., 2016). There is an expanding range of interest groups developing and using web thematic mapping resources to support scientific research and strategic planning (Smith, 2016; Voinov et al., 2016). In the Republic of Ireland (Ireland from here on), like in many other European Member States, the majority of such resources are disparate sites. They deal with a discrete set of socio-economic and/or environmental variables and their functionality is commonly limited to data visualisation and querying (see, for example, the Irish National Parks and Wildlife Service ${ }^{1}$ or Environmental Protection Agency $^{2}$ map viewers). This commonly results in one way communication channels where science may inform practice or practice may inform the wider public. The incorporation of interactive functionality can enhance science-practice exchanges and facilitate participative planning and decision-making. Although analytical functionality in online mapping sites remains generally basic due to both the current absence of geoprocessing tools in web-mapping libraries (Smith, 2016) and the technical expertise required to develop it (Swain et al., 2016), there is a growing deployment of specific web-based participatory spatial analysis tools across a wide range of research and practice areas (e.g. Babbar-Sebens et al., 2015; Ghaemi et al., 2009; Jetz et al., 2012; Labiosa et al., 2013; Rao et al., 2007; Simão et al., 2009; Sugumaran et al., 2004; Walker and Chapra, 2014). Voinov et al. (2016) provide a comprehensive review of recent developments in such web applications. Their main contribution to environmental assessment and planning is the provision of intuitive and interactive functionalities, promoting information transparency and stakeholder engagement. The advancement of client-side web applications, in particular, is enabling the provision of easy-to-use interfaces for the wider public (Walker and Chapra, 2014). This helps bringing down previous barriers to their effective use as Spatial Decision Support Systems (SDSS) in problem solving - resulting from the requirement of a priori knowledge and skills on geospatial data management, modelling and analysis.

Building on contemporary advancements in the development and delivery of geospatial analysis tools, we have developed an Environmental Sensitivity Mapping (ESM) web tool. The ESM web tool is available at http://airomaps.nuim.ie/id/ESM . ${ }^{3}$ Our goal with this GIS-based interactive platform is to enable a systematic, rapid and planspecific spatial examination of environmental considerations to support SEA, while facilitating transparency in science-practice communication.

\footnotetext{
${ }^{1}$ http://webgis.npws.ie/npwsviewer/.

2 https://gis.epa.ie/EPAMaps/.

${ }^{3}$ Access to the novel geoprocessing functionality described in this paper is currently limited; it will be publicly available in the ESM web tool's URL provided when the project is officially launched.
}

This is achieved by centralising over 100 SEA-relevant spatial datasets, and by simultaneously assessing multiple environmental receptors and their importance to examine the relative sensitivity of areas in a participative way. In doing so, the ultimate aim is to provide a reliable approach - which entails ensuring transparent, traceable and reproducible results (Mourhir et al., 2016), that steers development to suitable areas in the quest for sustainable development. The novelty of our client-side web tool is on its provision of geoprocessing capability not previously available online, and on its potential to overcome some of the common barriers to applying GIS in SEA and planning, such as the need for GIS expertise and resources and time requirements to collate, manage and analyse data (González, 2012).

With the underlying intention of openness and reproducibility, in this paper we present the web tool's methodological framework, architecture, and programming and data processing tasks required to provide geoprocessing capabilities online. We discuss some of the difficulties encountered when developing it and the fixes that have made it operational. We then describe the characteristics of this novel interactive SEAsupporting web tool by simulating the generation of context-specific sensitivity maps. Finally, we examine its advantages and shortcomings to enable a reflection on opportunities for further improving its functionality and applicability. Given that current literature commonly focuses on describing and demonstrating the applicability of end-products, this paper can contribute to advancing the deployment of geoprocessing tools in web-mapping libraries by addressing know-how limitations and, in this way, support innovation in web based modelling.

The remainder of the paper is organised as follows: Section 2 presents the methodological framework that forms the analytical basis of the web tool's sensitivity analysis geoprocessing functionality (referred to as the ESM widget from here on for simplicity). This is illustrated in the modelling workflow described in Section 3. Section 4 simulates a practical application to elaborate on its functionality, followed by a discussion in Section 5 on current limitations and potential future improvements, after which we make some concluding remarks.

\section{Methodological framework}

\subsection{Conceptualising environmental sensitivity}

There are a number of ways to conceptualise and measure sensitivity (e.g. Adger, 2006; Antunes et al., 2001; Yoo et al., 2014). Some authors emphasise the desirability of a system-approach that examines how, why and to what a given region is susceptible and that explores all interactions between receptors and stressors rendering such region environmentally sensitive (e.g. Adger, 2006; Aretano et al., 2015). Nevertheless, natural resource interactions and their adaptive capacity are complex and difficult to measure. Such complexity coupled with common data and resource limitations (González, 2012), render the majority of sensitivity analyses focusing on either the starting- or endpoints (e.g. Antunes et al., 2001; Geneletti et al., 2007; González et al., 
2011). They are implemented on the basis of discrete environmental criteria and indicators by either: a) determining the capacity of the land or resource to absorb change and remain on the same state (i.e. startingpoint); or b) establishing the acceptability of proposed human interventions by examining whether they positively or adversely effect change (i.e. end-point).

In order to develop a pragmatic tool for examining environmental sensitivity, we operationalised the concept on the basis of available knowledge and data. On this basis, we consider that existing legislative measures for environmental protection and risk avoidance (e.g. ecological designations protected under European law or flood risk), for which relevant data are available, can best inform sensitivity determinations in SEA (González, 2017b). This implies that, for example, the greater the degree of protection assigned to a natural resource, the more sensitive the area and the less capable of coping with land-use change ad adverse effects.

There is a growing uptake of spatial approaches in impact assessment (e.g. Atkinson and Canter, 2011; Geneletti et al., 2007; González et al., 2011; Marull et al., 2007; Sizo et al., 2016). This is probably a result of the increasing availability of spatial data and the sectoral uptake of GIS, but also due to the widely acknowledged benefits (e.g. Atkinson and Canter, 2011; González, 2012; Marull et al., 2007; Vanderhaegen and Muro, 2005). Geographically identifying areas that have higher risk of being adversely affected by anthropogenic change can provide new insights on impact significance and cumulative effects. Moreover, it can provide a robust baseline for developing alternatives that avoid sensitive sites or mitigate environmental effects from the onset. Such sensitivity analysis can be undertaken on the basis of detailed data and binary values (e.g. true/false) or adopt more flexible constraints (e.g. distance, importance values, etc.), also known as fuzzy suitability analysis (see Malczewski, 1999, 2002). The strategic nature of SEA commonly results in broad policies that often lack a spatial dimension or, at the most, include zoning of lands for specific development types but lack detail on densities, layout, design, resource consumption, etc. Such knowledge deficiencies on development specifics and uncertainties on the data, often constrain effective prediction of likely changes in SEA (i.e. focusing on the end-point). In light of this, spatially analysing the intrinsic susceptibility of the receiving environment to change provides a valuable starting-point; it helps addressing potential land-use conflicts at strategic planning level, as well as anticipating the significance of the proposed changes at project level (i.e. EIA), thus contributing to better informed decisions.

\subsection{Measuring environmental sensitivity}

In light of the conceptual and practical consideration above, and with the aims of reducing complexity, increasing understandability and promoting participation and joint exploration of environmental planning considerations (Mourhir et al., 2016; Wieland and Gutzler, 2014), we have adopted common multi-criteria approaches to impact assessment in the ESM analytical framework. We assume that the overall sensitivity of an area relates directly to the number of sensitive factors overlapping at that location - each multiplied, where applicable, by the relative importance (i.e. weight) assigned to it by experts and/or stakeholders. To achieve this, we apply a multi-criteria weighted linear combination algorithm that avoids normalisation (González et al., 2011; Wang et al., 2008):

$\mathrm{ESI}=\sum_{1}^{n} S_{c j} W_{j}$

where:ESI refers to the environmental sensitivity index that captures the overall sensitivity for the area, which relates to the total number (n) of criteria that overlap at that location; $\mathrm{S}_{\mathrm{cj}}$ is the susceptibility score for criterion $\mathrm{j}$ according to legislative resource protection measures or scientific values on risk (i.e. scientifically-grounded considerations); and. $\mathrm{W}_{\mathrm{j}}$ is the public weighting of subjective nature on the importance/ significance of criterion $\mathrm{j}$.

Normalising the total sensitivity of a given area, that is dividing it by the number of issues co-occurring at that given location, allows for trade-offs between criteria (Malczewski, 1999), but it can neglect significant sensitivities as well as cumulative effects. To avoid this, the division factor that averages the output value is not included in the algorithm. In the ESM approach, we focus on the spatial dimension when assessing the potential for cumulative effects. This is determined on the basis of the spatially concentrated environmental criteria, meaning that the aggregated sensitivity of the receiving environment (and hence the potential for cumulative adverse effects) directly relates to the number of overlapping environmental sensitivities. For example, a proposed land-use zoning for the future development of industrial and commercial facilities sitting on a highly vulnerable aquifer and poor surface water quality catchment, with areas likely to contain protected habitats and archaeological sites will potentially lead to cumulative adverse effects on biodiversity, water and cultural heritage.

To facilitate aggregation of criteria for producing sensitivity maps, we developed susceptibility scores in order to harmonise the relative susceptibility of each criterion. Given their fixed nature (i.e. they cannot be modified by the web tool user), necessary to facilitate a consistent combined analysis, we sought consensus on their relative values. To achieve this, two national workshops were held engaging 43 practitioners, researchers and governmental representatives. They were identified and invited to participate on the basis of their SEA roles and disciplinary expertise (e.g. ecology, water, air, etc.). We put forward preliminary scores (i.e. 1 to 3 relating to low, moderate and high) to the consulted stakeholders for their review and discussion. These were based on statutory thresholds, targets, designations and risk. For example, Special Protected Areas designated under the European Habitats Directive were assigned a high score of 3 , while poor status waters under the Water Framework Directive were assigned scores of 2 -i.e. moderate. The applied harmonisation rules assume that the greater the sensitivity of an environmental criterion, the higher the score assigned to it. Structured stakeholder consultation facilitated building consensus on the susceptibility scores, which are the foundation of the ESM (see González, 2017b for full detail).

We included a subjective weighting option of SEA themes in the web tool to factor in SEA scoping priorities or individual concerns and thus facilitate the mandatory requirement for public participation (EC, 2003). This option enables magnifying the sensitivity of a given environmental theme by means of context-specific user-defined weights on the relative importance assigned to the theme. For simplicity and user-friendliness, two weighting options are provided: 1 to maintain the susceptibility scores; and 2 to emphasise the importance (associated with public values or concerns) of a given theme in comparison to other/s included in the analysis. Stakeholders felt that this "emphasis" was sufficient to highlight relevant considerations as the weight doubles the scores of selected environmental criteria, intensifying the overall sensitivity of the related areas (González, 2017b).

\section{Developing an environmental sensitivity mapping web tool and widget}

The architecture and design of online environmental planning tools are commonly based on the client/server technology, whereby data querying, geoprocessing, and spatial data analysis are implemented at the server-side and user interaction and data display are the end-processes executed at the client-side (Ghaemi et al., 2009). The ESM web tool adopts this same structure, expanding the basic data visualisation functionality of the client-side by enabling user input on decision criteria and their relative importance (i.e. weights) through the incorporation of a novel ESM widget, which aligns with contemporary interactive online mapping applications (e.g. Simão et al., 2009; Walker and Chapra, 2014). 


\subsection{System architecture}

Although commonly various technologies are used to develop clients and servers (Ghaemi et al., 2009), the ESM web tool has been developed using a suit of ArcGIS Desktop and Online services (Fig. 1). On the server-side, the geoprocessing application that operates the ESM widget was developed using ModelBuilder in ArcGIS 10.5 and then published as a geoprocessing task to ArcGIS for Server. Using ArcGIS Web AppBuilder (Developer Edition), this task was configured and integrated into a customised widget for use within the ESM web tool. The ESM web tool is developed using the ArcGIS API for Javascript which combines state-of-the-art web-mapping technology and contemporary geospatial capabilities.

\subsection{Workflow design}

\subsubsection{Data geoprocessing and model building}

We designed a workflow to structure data collection and preparation in ArcGIS Desktop. The ESM web tool relies on existing available datasets downloaded from public sources or requested to public agencies (Table 1). Once sourced, datasets were pre-processed to facilitate their manipulation within the online platform; this entailed, among other things, data cleaning, and attribute and projection standardisation. For example, it was necessary to merge and dissolve datasets for some criteria that contained various data sources (e.g. designated habitats or peatlands). And we often had to edit attribute tables to standardise nomenclature or to incorporate a new field for those datasets containing features that required the assignment of various susceptibility scores (e.g. aquifer vulnerability was harmonised by assigning a score of 3 to extreme/high, 2 to moderate and 1 to low vulnerability aquifers). The multiple datasets sourced for inclusion in the ESM web tool have diverging spatial reference systems (e.g. Irish Transverse Mercator, Irish National Grid or World Geodesic System, 1984). To ensure geographical consistency, all datasets were projected to the Web Mercator projection (WGS 1984 Web Mercator (auxiliary sphere)) used in and required by the ArcGIS Online (AGOL) web viewer. We used ArcGIS ModelBuilder to develop data processing models and thus automate the desktop task of processing multiple datasets. With all preprocessing and data cleaning tasks completed, we created eight SEArelevant thematic projects (.mxd ArcGIS project files for landscape, water, etc.) containing multiple individual feature layers, and recording symbology, labelling and other feature properties that determine their display in the web viewer. Each ArcGIS project file, and its associated vector datasets and metadata (put in place to provide pop-up content in the layer list component of the web viewer - Table 2), was subsequently saved in the local server as specific geodatabases for each SEA theme.
These geodatabases form the basis for the ESM web tool viewer.

The next stage involved using data conversion tasks in ArcGIS Desktop to create raster files for the ESM widget. The conversion from vector to raster is necessary to allow map algebra (i.e. spatially additive data processing and relative sensitivity calculations using the weighted linear overlay algorithm on which the widget is based). The vector shapefiles of the previously generated geodatabases were inputs to this process, which generated $100 \mathrm{~m} \times 100 \mathrm{~m}$ resolution masked and snapped (to $10 \mathrm{Km}$ outside the Irish coastline) raster files. We adopted this cell size as it reasonably represents environmental and land-use processes and patterns at the landscape scale, and is commonly used in regional and county level environmental assessments (e.g. Antunes et al., 2001; Geneletti et al., 2007; González et al., 2011). Raster calculator tools were concatenated to assign the previously defined susceptibility scores to the appropriate grid cells in the raster models. The output raster files were saved in a new geodatabase for each SEA theme.

\subsubsection{Web tool data viewer}

The entire ESM web tool viewer is developed using the ArcGIS API for Javascript environment. The previously created individual project files for the vector datasets were published as a 'service' to ArcGIS for Server which gave each thematic project file a unique and web accessible endpoint. Using an AGOL user account. We created a specific web map to host the published ESM content by adding the unique web endpoints from the ArcGIS web endpoint or REST Service Directory. At this point, we configured an attribute pop-up for each feature in the AGOL web map in order to facilitate user data queries by reading relevant fields from the attribute table associated to each dataset (Fig. 2). We also configured pop-up windows in AGOL, with metadata collated for each dataset in order to provide users a contextual justification of their inclusion, as well as to present details on the source of data, their creation/collection date and susceptibility scores assigned to them (Table 2).

Once the AGOL web map was configured, we created a web application to host it and thus provide user interface and basic functionality. We developed and designed it using ArcGIS Web AppBuilder, and incorporated additional functionality through pre-established ArcGIS widgets to enable users to: navigate, annotate and print the map; access Google Street View; and upload user data. The bespoke geoprocessing ESM widget, for creating environmental sensitivity maps "on-the-fly" for any selected region in Ireland (details of the widget's raster algebra model are provided in the next section), was added at this point. In addition, we developed a specific 'print' widget to integrate the results from the ESM widget and allow users to print out the sensitivity map results. This bespoke print widget captures the environmental criteria brought into the assessment and the weights applied (Fig. 6).



Fig. 1. Basic functional architecture of the ESM web tool. 
Table 1

SEA themes and associated environmental datasets incorporated in the ESM web tool.

\begin{tabular}{|c|c|c|}
\hline Data Source & Download link & Spatial Datasets in the ESM \\
\hline \multicolumn{3}{|l|}{ SEA theme: Air and Climate } \\
\hline Environmental Protection Agency & https://gis.epa.ie/EPAMaps/ & Air zones Coal restricted areas \\
\hline National Parks and Wildlife Service & $\begin{array}{l}\text { http://dahg.maps.arcgis.com/apps/MapSeries/index.html?appid = } \\
\text { cb5040a4a19645b6b424bed940c54fff }\end{array}$ & $\begin{array}{l}\text { Soil carbon (ecosystem service) Vegetation carbon } \\
\text { (ecosystem service) Water retention (ecosystem } \\
\text { service) }\end{array}$ \\
\hline Office of Public Works & htpp://www.floodmaps.ie & Historical flood extents \\
\hline $\begin{array}{l}\text { Sustainable Energy Authority of } \\
\text { Ireland }\end{array}$ & Provided on request & Wind speeds \\
\hline \multicolumn{3}{|l|}{ SEA theme: Biodiversity, Flora and Fauna } \\
\hline BirdWatch & $\begin{array}{l}\text { http://www.birdwatchireland.ie/OurWork/PolicyAdvocacyanoverview/ } \\
\text { BirdSensitivityMapping/tabid/1312/Default.aspx }\end{array}$ & Birdwatch sensitivity (to wind farms) \\
\hline $\begin{array}{l}\text { Department of Agriculture, Food and } \\
\text { the Marine }\end{array}$ & Provided on request & Forest inventory \\
\hline National Parks and Wildlife Service & https://www.npws.ie/maps-and-data/habitat-and-species-data & $\begin{array}{l}\text { Ancient woodlands Annex I habitats (Habitats } \\
\text { Directive) Coastal habitats - Saltmarshes } \\
\text { Margaritifera sensitive areas Natural Heritage Areas } \\
\text { Proposed Natural Heritage Areas Salmonid waters } \\
\text { Special Areas of Conservation (SACs) Special } \\
\text { Protection Areas (SPAs) Woodland habitats }\end{array}$ \\
\hline National Parks and Wildlife Service & $\begin{array}{l}\text { http://dahg.maps.arcgis.com/apps/MapSeries/index.html?appid = } \\
\text { cb5040a4a19645b6b424bed940c54fff }\end{array}$ & $\begin{array}{l}\text { Contributions to potential ecological networks } \\
\text { (ecosystem services) Legally protected and policy } \\
\text { relevant species (ecosystem services) Terrestrial } \\
\text { biodiversity (ecosystem services) }\end{array}$ \\
\hline \multicolumn{3}{|l|}{ SEA theme: Cultural Heritage } \\
\hline $\begin{array}{l}\text { Department of Culture, Heritage and } \\
\text { the Gaeltacht }\end{array}$ & http://www.buildingsofireland.ie/Surveys/Buildings/NIAHDataDownload/ & National Inventory of Architectural Heritage \\
\hline $\begin{array}{l}\text { http://webgis.archaeology.ie/ } \\
\text { nationalmonuments/flexviewer/ }\end{array}$ & Sites and Monuments Record & \\
\hline $\begin{array}{l}\text { Data generated based on an existing } \\
\quad \text { report }\end{array}$ & World Heritage Sites & \\
\hline Heritage Council & https://heritagemaps.ie/w & $\begin{array}{l}\text { Irish Landmark Trust Museums, collections and } \\
\text { archives Walled towns }\end{array}$ \\
\hline \multicolumn{3}{|l|}{ SEA theme: Landscape } \\
\hline Local authorities & $\begin{array}{l}\text { Data sourced from each local authority and merged on the basis of landscape } \\
\text { sensitivity }\end{array}$ & Landscape character areas \\
\hline \multicolumn{3}{|l|}{ SEA theme: Material Assets } \\
\hline Environmental Protection Agency & http://gis.epa.ie/GetData/Download & $\begin{array}{l}\text { Discharge licences Extractive industries register } \\
\text { Historic mine districts Integrated Pollution Prevention } \\
\text { and Control (IPPC) licences Landfill sites Licensed } \\
\text { waste facilities Waste water treatment plants and } \\
\text { status }\end{array}$ \\
\hline Geological Survey of Ireland & https://www.gsi.ie/en-ie/data-and-maps/Pages/default.aspx & Active quarries \\
\hline $\begin{array}{l}\text { Sustainable Energy Authority of } \\
\text { Ireland }\end{array}$ & Provided on request & Current wind farms \\
\hline Ordnance Survey of Ireland & https://data.gov.ie & $\begin{array}{l}\text { Airfields and airports Broadband access Ports Railway } \\
\text { network Road Network Settlements }\end{array}$ \\
\hline \multicolumn{3}{|c|}{ SEA theme: Population and Human Health } \\
\hline Central Statistics Office & http://cso.ie and http://airo.maynoothuniversity.ie/datastore & $\begin{array}{l}\text { Disability General health Housing stock (vacant and } \\
\text { holiday homes) Labour force unemployed Pobal HP } \\
\text { Deprivation Index Population change Population } \\
\text { density per Km2 Total population }\end{array}$ \\
\hline Environmental Protection Agency & http://gis.epa.ie/GetData/Download & $\begin{array}{l}\text { Water Framework Directive (WFD) Record of } \\
\text { Protected Areas (RPA): groundwater and surface lakes } \\
\text { and rivers, drinking water }\end{array}$ \\
\hline \multicolumn{3}{|l|}{ SEA theme: Soils and Geology } \\
\hline Environmental Protection Agency & http://gis.epa.ie/GetData/Download & $\begin{array}{l}\text { CORINE landcover Peat bogs Soil permeability Soils } \\
\text { Geological Survey of Ireland https://www.gsi.ie/en- } \\
\text { ie/data-and-maps/Pages/default.aspx } \\
\text { Bedrock Landslide events and susceptibility Mineral } \\
\text { locations }\end{array}$ \\
\hline $\begin{array}{l}\text { Geological Survey of Ireland } \\
\text { SEA theme: Water }\end{array}$ & https://www.gsi.ie/en-ie/data-and-maps/Pages/default.aspx & Geoparks Geosites Outcrops \\
\hline Environmental Protection Agency & http://gis.epa.ie/GetData/Download & $\begin{array}{l}\text { Biological Q (quality) values Hydrometric areas } \\
\text { Wetlands WFD groundwater, lake and river risk WFD } \\
\text { groundwater, lake and river status WFD RPA: Nutrient } \\
\text { sensitive areas (coastal, lakes, rivers and transitional } \\
\text { water bodies) WFD RPA: Recreational waters (coastal, } \\
\text { lakes and transitional water bodies) WFD RPA: } \\
\text { Shellfish areas WFD RPA: Water dependent habitats } \\
\text { SACs and SPAs Water management Units }\end{array}$ \\
\hline Geological Survey of Ireland & https://www.gsi.ie/en-ie/data-and-maps/Pages/default.aspx & $\begin{array}{l}\text { Aquifer vulnerability Bedrock aquifer Bedrock aquifer } \\
\text { susceptibility Groundwater source protection areas } \\
\text { Water abstraction points }\end{array}$ \\
\hline
\end{tabular}


Table 2

Metadata specifications gathered for the ESM datasets.

\begin{tabular}{|c|c|c|}
\hline Metadata Field & Description & ESM pop-ups \\
\hline Source & Data creator or collector (e.g. agency, institution) & Yes \\
\hline Download link & URL for downloading the dataset in shapefile format & No \\
\hline REST Service (web endpoint) & RESTful web service for automatic notification of data updates & No \\
\hline Date & Date of the last data update as indicated by the data source & Yes \\
\hline Associated legislation & European and national directives and regulations associated to the dataset & No \\
\hline Definition & Brief description of the dataset and an outline of its relevance to SEA & Yes \\
\hline Data preparation & Details on the data cleaning and completion tasks undertaken to ensure datasets were fit for use & No \\
\hline Susceptibility scores & $\begin{array}{l}\text { Degree of sensitivity of each environmental criteria or variable (i.e. dataset) standardised to } 1 \text { (low), } 2 \text { (moderate) and } 3 \text { (high) } \\
\text { and agreed through stakeholder consultation }\end{array}$ & Yes \\
\hline
\end{tabular}

\subsubsection{Developing the ESM widget}

This novel functionality was initially developed using a series of geoprocessing tools within ArcGIS Desktop ModelBuilder. Once the model accurately produced the required sensitivity results, we integrated the published geoprocessing task within a bespoke front end Graphical User Interface (GUI) within the web tool (Fig. 3). The published geoprocessing task provides users with a series of options on the client-side - the ability to select: 1 ) the study area of interest; 2) the SEA-relevant criteria or variables they are interested in; 3) the weights they wish to apply; and finally 4) a 'Go' button which activates the geoprocessing task on the server-side.

On activation of the 'Go' button two main sets of information are sent to the server-side geoprocessing model: a) the variables and weights to be included in the model and b) the selected study area. The overall model flow from user interaction with the GUI to final map output is outlined in Table 3.

The overall development of the ESM model and associated spatial analysis components (raster calculation, raster collection, clip, etc.) was a relatively simple process and based on a standard set of geoprocessing techniques. The integration of these published geoprocessing tasks into the ESM web tool was also straight forward within the ArcGIS Web AppBuilder infrastructure. However, we encountered a significant number of technical difficulties when developing the integration between the GUI on the client-side and the process logic of the model on the server-side (e.g. transferring the selected criteria and weights in the bespoke GUI to the ESM model in ArcGIS for server). To link these two processes, we had to develop specific sets of code to enhance the standard 'out of the box' widgets available within ArcGIS Web AppBuilder. We also had to develop specific code that integrated the output from the ESM model (i.e. the sensitivity map) into a standard print widget. Both of these tasks required expert technical,

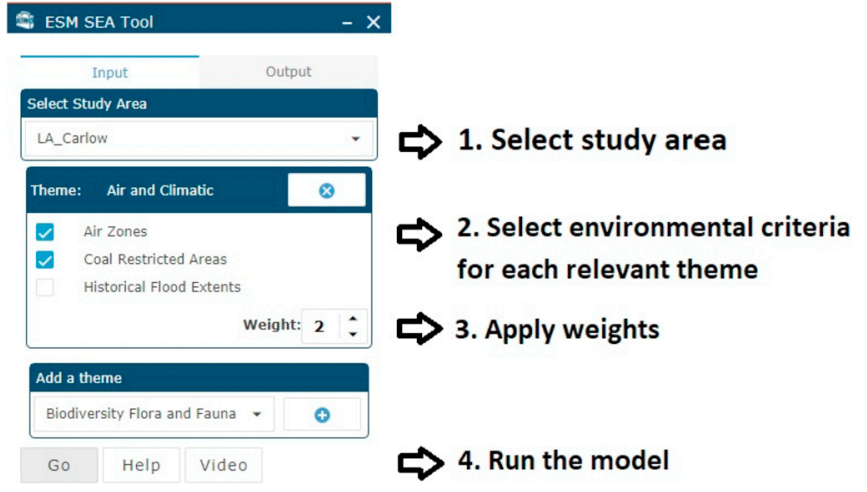

Fig. 3. Graphical User Interface of the ESM widget.

programming and software development knowledge of the ArcGIS API for Javascript environment - which a normal GIS analyst or environmental scientist would not be exposed to.

\subsection{Summary of functionality}

The web tool provides two core functionalities that are of value to SEA: (1) a geographic exploration of the characteristics and distribution of environmental resources (Fig. 5); and (2) an examination of relative environmental sensitivities for a given area (Fig. 6). Centralisation of SEA-relevant datasets is the core benefit of the former, and instant generation of plan-specific sensitivity maps a novel approach in the latter.

Centralised access to over 100 publicly available spatial datasets relevant to the thematic requirements of the SEA Directive (EC, 2001) supports and facilitates environmental assessment practice in Ireland. These datasets were selected purely on the basis of their SEA relevance

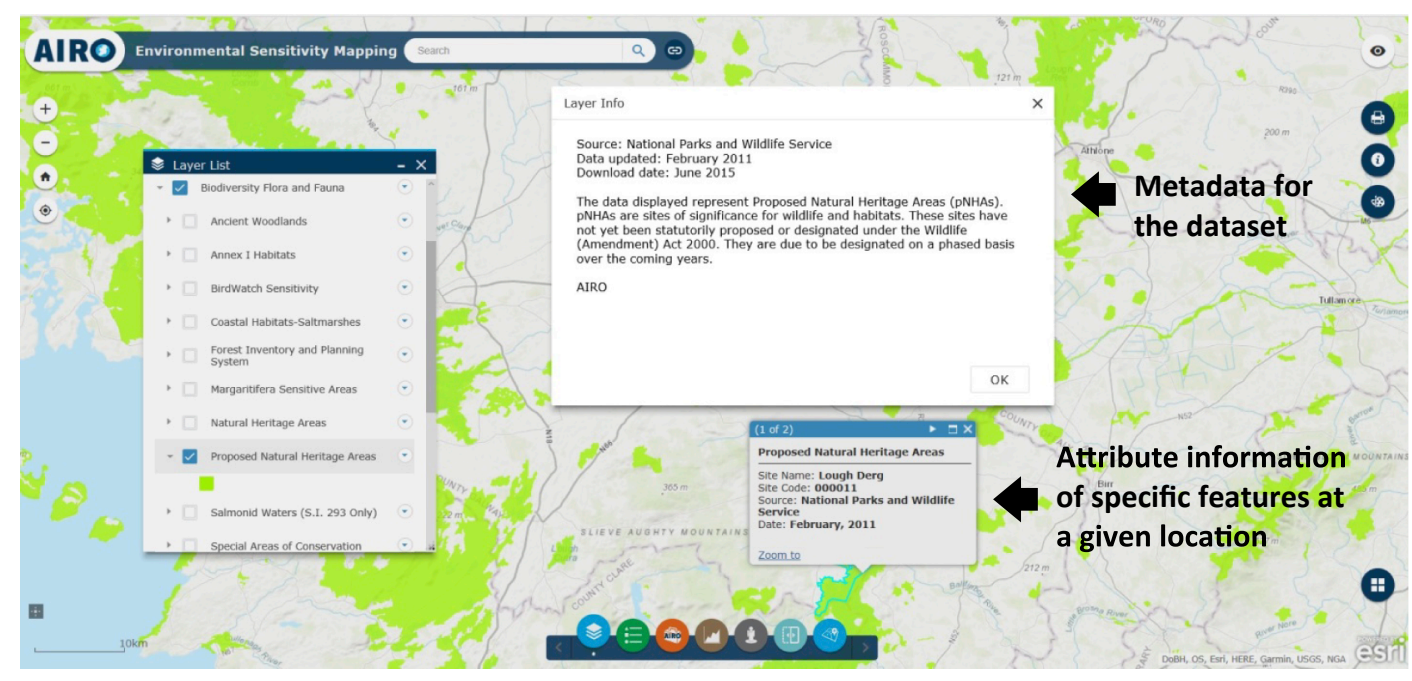

Fig. 2. Sample ESM pop-up windows for attributes and metadata. 
Table 3

Environmental Sensitivity Map (ESM) model process and description of the various steps.

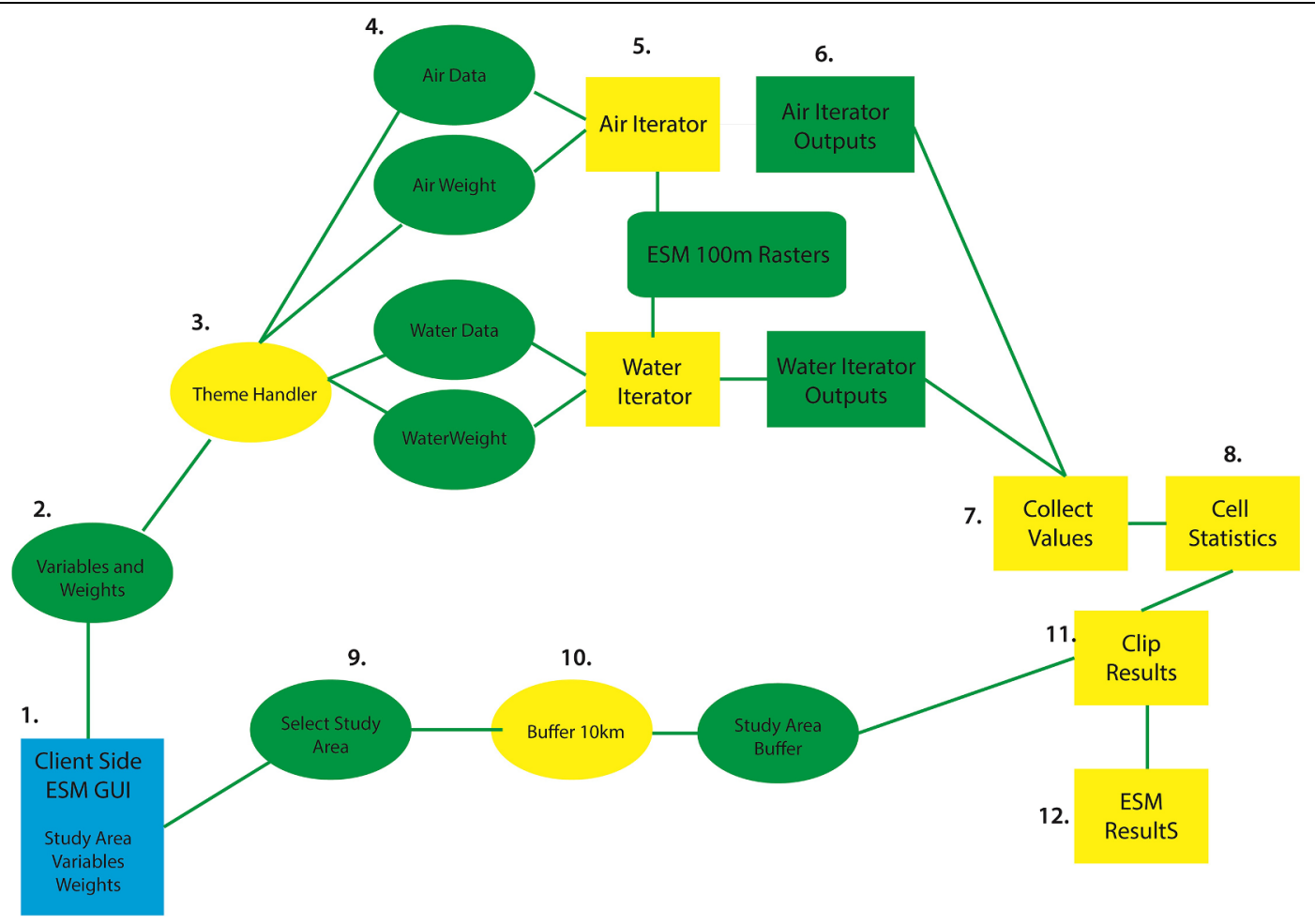

\begin{tabular}{|c|c|}
\hline Step & Description of tasks \\
\hline Step 1 & $\begin{array}{l}\text { By interacting with the GUI, the user selects the variables of interest and relevant weights to be used in the analysis. This information is stored in a JSON file and } \\
\text { sent to the geoprocessing model on the server (step 2). The GUI also requires the selection of specific pre-defined study area geography. This variable name is also } \\
\text { stored and sent to the geoprocessing model during the final stages of processing (step 9). }\end{array}$ \\
\hline Step 2 & $\begin{array}{l}\text { The JSON file ('Variables and Weights') contains information on all of the themes, variables and weights selected for use in the analysis. This is the main set of } \\
\text { parameters for the model and comes directly from the client-side GUI. }\end{array}$ \\
\hline Steps $3 \& 4$ & $\begin{array}{l}\text { A ThemeHandler.py file takes the input from the JSON file and creates a series of parameter files for each of the SEA themes (this working example only details Air } \\
\text { and Water themes - for full set of themes refer to Table 1). It basically splits the content of the JSON file up and sends the relevant components (criteria and } \\
\text { weights) to the different sub-models for each theme. Two parameters are set for each theme - the list of variables ('Air Data') and the weight to be applied ('Air } \\
\text { Weight'). }\end{array}$ \\
\hline Steps $5 \& 6$ & $\begin{array}{l}\text { A specific 'iteration' raster calculation process is then carried out for each selected variable within all SEA themes (refer to Fig. } 4 \text { for details on the model process in } \\
\text { ArcGIS ModelBuilder). For instance, within the 'Air Iterator' process the model calls each raster layer listed in 'Air Data' from the 'ESM } 100 \mathrm{~m} \text { Raster.gdb' (this } \\
\text { contains all pre-processed raster layers with susceptibility scores) and creates a new raster layer for each layer. This entails multiplying the susceptibility scores } \\
\text { pre-assigned to the rasters (i.e. } 1 \text { to } 3 \text { for each } 100 \mathrm{~m} \text { cell) by the user-defined weights stored in 'Air Weight'. Each new layer is then stored in a new set of } \\
\text { parameters in 'Air Iterators Output'. }\end{array}$ \\
\hline Step 7 & $\begin{array}{l}\text { Once all the new raster layers have been processed for each variable and theme, the results are all collected using a 'Collect Values' geoprocessing tool. This tool } \\
\text { essentially stores all of the results from 'Air Iterator Output', 'Water Iterator Output', etc. }\end{array}$ \\
\hline Step 8 & $\begin{array}{l}\text { The model uses cell statistics to create an aggregate total (sum of all the raster calculations - i.e. scores and weights, rendering the environmental sensitivity index) } \\
\text { for each } 100 \mathrm{~m} \text { pixel. }\end{array}$ \\
\hline Steps $9 \& 10$ & $\begin{array}{l}\text { This part of the model takes the selected study area name (e.g. a region, local authority or river basin district as defined by the user in the GUI), calls the relevant } \\
\text { layer from the ESM_Geographies.gdb on the server and creates a new individual vector layer with a } 10 \mathrm{~km} \text { buffer. The model includes a } 10 \mathrm{~km} \text { buffer in this process } \\
\text { to ensure output data are available for areas outside the study area boundary (and thus capture potential transboundary sensitivities). }\end{array}$ \\
\hline Step 11 & The last data processing task, 'Clip Results', entails clipping the cell statistics results to the specified study area buffer. \\
\hline Step 12 & $\begin{array}{l}\text { The final step within the model renders a sensitivity index map output, which is subsequently displayed on the web tool viewer and integrated within the ESM- } \\
\text { specific print widget for final display and annotation. }\end{array}$ \\
\hline
\end{tabular}

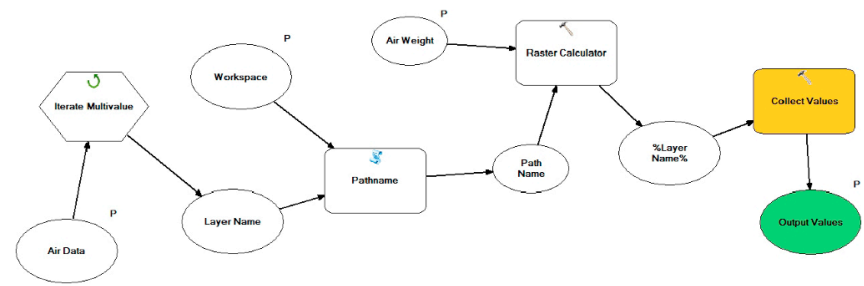

Fig. 4. ArcGIS ModelBuilder iteration task (step 5 in Table 3) for collecting raster calculations based on user-selected layers and weights and producing new raster outputs. and public accessibility and obtained from an array of governmental sources (Table 1). All these datasets can be interrogated in the web tool - i.e. the end-user can turn on/off datasets for their individual or combined visualisation and print out, as well as click on a given area to obtain information on its main characteristics (e.g. description, typology and status of environmental factors at that location) (Fig. 5). More importantly, a subset of these datasets can be combined in the widget to generate plan-specific sensitivity maps. The analysis can be adjusted to geographical envelopes by applying it to the island of Ireland or to specific regions (e.g. counties or townlands). The ESM widget GUI (Fig. 3) enables the user to select a study area and, subsequently, SEA themes and criteria (i.e. spatial datasets), as well as to assign any 


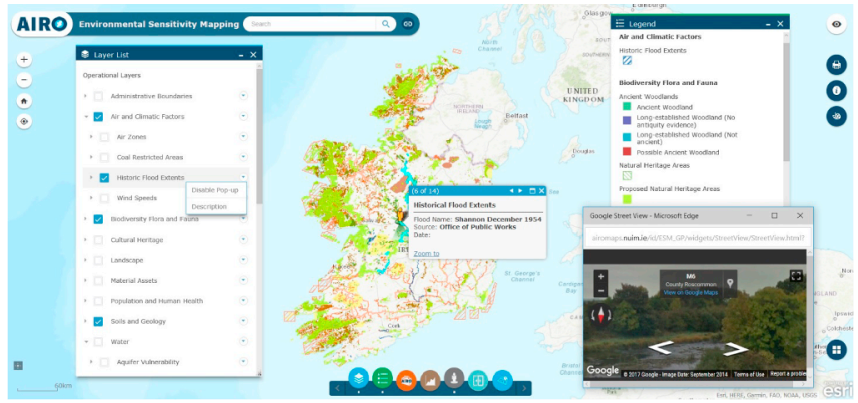

Fig. 5. ESM web tool viewer with a sample of data querying and visualisation pop-up windows.

subjective relative importance weights that address plan/programme considerations. The sensitivity analysis results are presented in raster format on the web tool viewer. To facilitate comparability of results across geographical areas, we adopted a fixed-breaks categorisation index for ranking environmental sensitivity outputs. This index is static and provides a composite illustration of relative degrees of accumulated sensitivity across space (Fig. 6). As previously noted, the overall sensitivity of a given area directly relates to the number of overlapping criteria and their assigned weights; criteria susceptibility scores range from 1 to 3 and weights are limited to 1 and 2. Therefore, the very low overall sensitivity index infers a single high susceptibility criteria assigned a neutral weight (i.e. $3 \times 1$ ), or a low susceptibility criteria given greater weight $(1 \times 2)$. Low overall sensitivity may relate, for example, to two highly susceptible criteria neutrally weighted $((3 \times 1)+(3 \times 1))$, or to two low susceptibility criteria weighted $((1 \times 2)+(1 \times 2))$. And so on.

The raster outputs can also be saved as a map layout that includes a list of the selected themes, criteria and weights brought into the

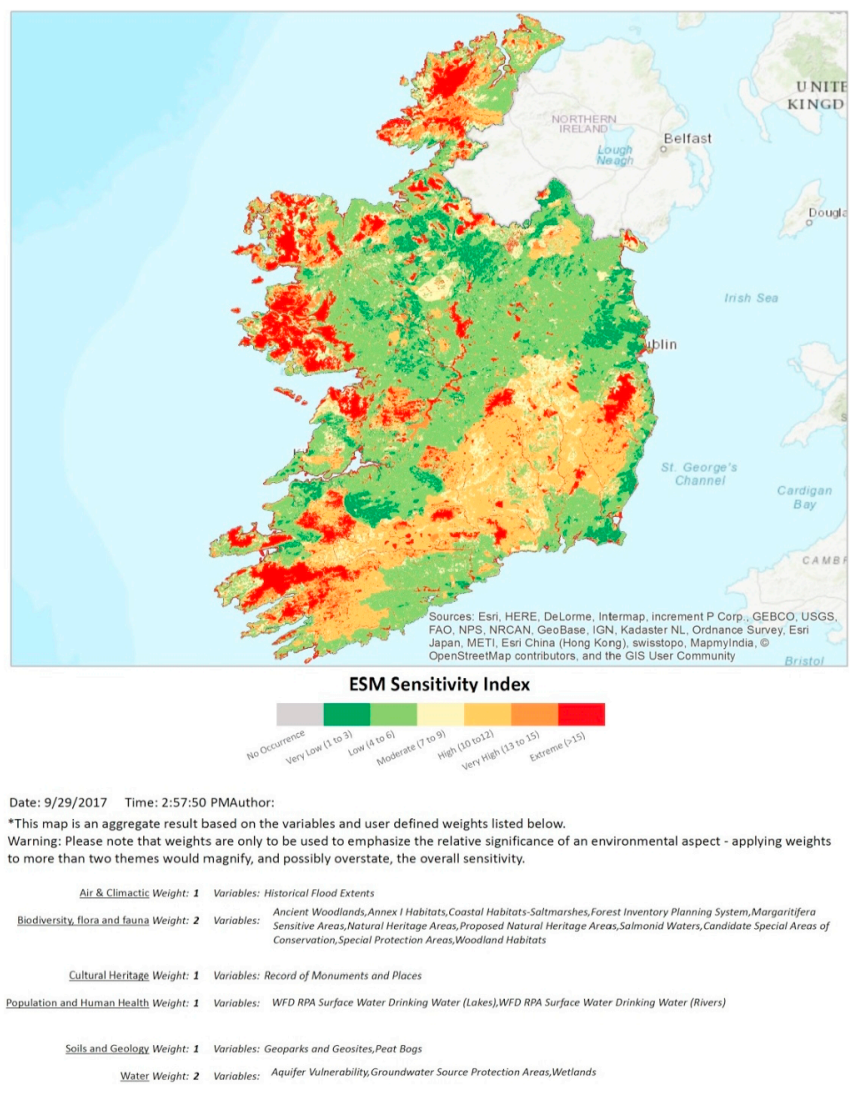

Fig. 6. Sample map output from the ESM web tool. assessment by the user. This contributes to ensuring transparency, and facilitates interpretation of the index and map. Date of map creation and authorship are also recorded; the latter is required so that map authors can defend the rational for using the selected criteria/weights and the resulting mapped output (Fig. 6).

\section{Application and outputs}

The web tool and widget are, in principle, applicable to various sectoral plans and programmes across planning hierarchies. The ESM widget enables context-specific examination of environmental sensitivity following SEA requirements, supporting good practice for meaningful and focused assessments (e.g. Jones et al., 2005; Therivel, 2004). Criteria and weights are main inputs to the sensitivity analysis algorithm and, as such, they define the relative sensitivity of the different areas. Missing to consider key issues (i.e. susceptible criteria) and factoring in public values (e.g. concerns) shapes outputs. For example, in the hypothetical scenario of a sectoral strategy to intensify commercial forestry plantations in Ireland's Southern region, key susceptibilities in the receiving environment would relate to biodiversity (e.g. from natural habitat replacement) and water (e.g. contamination risk from fertilisers). Yet the potential to adversely affect cultural heritage (e.g. damage to or screening of protected monuments) and soils and geology (e.g. plantation on peat bogs), for example, may also need to be considered - although stakeholders may place greater importance to protecting biodiversity and water resources. In this example, overlooking cultural heritage, soils and geology (or indeed assigning various significance weights) leads to various contextual sensitivity maps (Fig. 7). Therefore, informed and consensual values should be implemented. In any case, the ESM widget can be repeatedly applied, varying the criteria and weights brought into the assessment, as appropriate. This enables examination of how different considerations and (changing) importance values may alter the relative sensitivity of the receiving environment and, in this example, the relative suitability of the various areas for commercial forestry plantations.

The ESM outputs support SEA processes by identifying areas that are susceptible to change according to local intrinsic sensitivities and concerns. They can better inform the development of plan/programme alternatives that direct development away from these areas, promoting environmental protection and sustainability. Similarly, they can

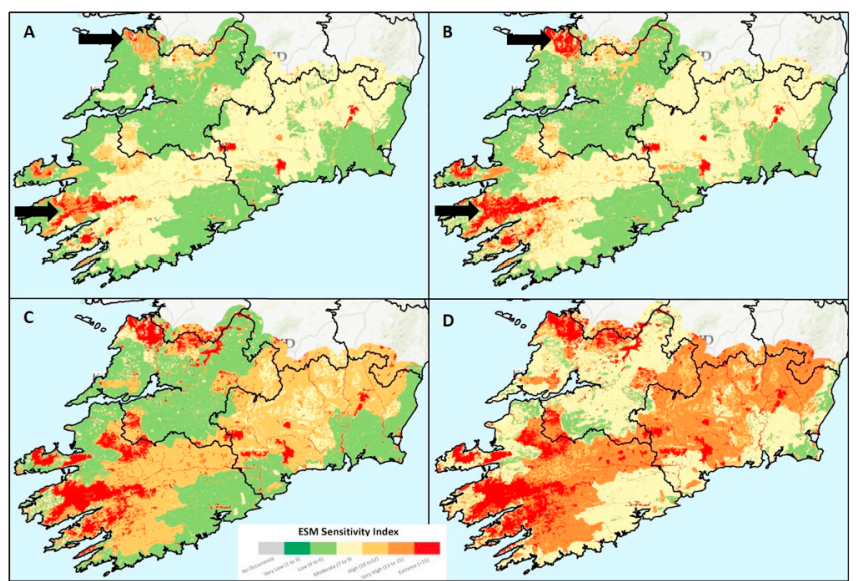

Fig. 7. Sample ESM widget outputs illustrating contextualised environmental sensitivity maps for the Southern region of Ireland: (a) biodiversity, flora and fauna and water sensitivities; (b) sensitivities associated with biodiversity, water, cultural heritage and soils - where all have the same weight/importance; and (c) sensitivities associated with biodiversity, water, cultural heritage and soils - where the biodiversity themes is given greater importance (i.e. a weight of 2); and d) sensitivities associated with biodiversity, water, cultural heritage and soils - where both the biodiversity and water themes are given greater importance (i.e. a weight of 2). 
provide the baseline background against which planning alternatives can be systematically assessed by overlapping proposed land-use changes with the accumulated intrinsic sensitivity of the receiving environment. This approach can help determine the best/worst alternative in environmental terms, and the potential for cumulative effects of each alternative.

The above entirely hypothetical simulation illustrates how criteria and weights shape outputs and, ultimately, decisions. However, this flexibility is necessary for participative decision-making (Mourhir et al., 2016). At a practical level, the web tool has been pilot tested in the land-use and wind energy planning sectors, by applying it to recently completed SEAs in these sectors and comparing outputs. For this purpose, two sectoral workshops took place, where stakeholders (i.e. planners and SEA consultants) were asked to apply the web tool to mimic previously undertaken SEAs (i.e. by applying the same criteria and weights in so far as possible) and to provide feedback. Workshop participants commended the functionality of the web tool, highlighting the time and resource advantages derived from the centralisation of SEA-relevant data and from the possibility to visualise and query them without the need for GIS skills. They also validated and recognised the value in the applicability of the outputs with regards to the identification of most/least environmentally susceptible areas as a means to make informed and more environmentally-robust planning decisions (see González, 2017a for details). Nevertheless, they also observed that the data currently available in the web tool favour its application to SEA of land-use plans. Inclusion of additional datasets (e.g. landscape character areas, distance from housing, soil capacity, etc.), as these become publicly available, was recommended in order to enhance its applicability to other sectors such as renewable energy and forestry.

\section{Discussion}

While there is an increasing availability of web-based GIS applications that facilitate participatory environmental criteria examination and modelling (Smith, 2016; Voinov et al., 2016), this operational decision support tool ties in to the specific legal requirements of SEA processes. And by providing a more transparent and accountable evidence-base for decisions, it has the potential to enhance both environmental assessment and planning practice. In particular, it presents an innovative step forward to enhance Irish SEA practice by: a) facilitating access to data; b) enabling a pragmatic and systematic analysis of environmental sensitivity; c) providing easy to apply GIS methods to examine spatial conflicts; and d) encouraging participatory deliberation on environmental significance. What really matters in a multi-criteria framework is facilitating participation and sharing of knowledge, communicating stakeholder opinions on environmental issues and providing easy-to-understand and traceable outputs to decision-makers. These are all critical aspects for a democratic process towards consensus, since the problem structuring will determine the ultimate result (Mourhir et al., 2016; Munda, 2004). In other words, it is essential to facilitate good science-practice communication; and the ESM web tool supports this principle.

Graphic display and querying capabilities are becoming widely available on the web but online SDSS that include dynamic geoprocessing power are rather limited (Smith, 2016), albeit emergent (Voinov et al., 2016). Online provision of user-friendly spatial data query and processing tools, such as the ESM web tool presented here, can help break down some of the identified barriers to the effective application of GIS in impact assessment and planning (González, 2012; Riddlesden et al., 2012). And they can advance the know-how on and deployment of advanced online geoprocessing functionality. Such tools can facilitate access to SEA-related data and information, with the potential to enhance information delivery for better decisions (Vicente and Partidário, 2006). They provide the opportunity for stakeholders (e.g. planners, decision-makers, community groups and NGOs) with little or no GIS expertise to apply spatial analysis tools to query and examine such data and, in this way, promote participation and collaborative planning (Atkinson and Canter, 2011; Batty, 2013; Ghaemi et al., 2009; González, 2017a; Mourhir et al., 2016; Voinov et al., 2016). The ESM web tool has other added benefits, such as the rapid generation of plan/programme-specific sensitivity maps in a matter of minutes (regardless of the user's GIS experience), replicability of analyses and comparability of outputs.

The composite illustration of spatially accumulated sensitivity contributes an additional dimension to current baseline studies in SEA and, more importantly, it facilitates a systematic assessment of the potential for cumulative effects of different planning alternatives. The resulting easy-to-understand environmental sensitivity index provides early warning on potential land-use conflicts and, as noted above, can help steer development away from the most sensitive locations. Such aggregated index may, in principle, result in individual environmental criteria being obscured, affecting interpretation (Boggia et al., 2018). However, the ESM web tool viewer permits identifying and querying the environmental criteria that co-occur at a given location, and in this way enables scrutinising all underlying sensitivities, as well as tracing and meaningfully interpreting outputs (Fig. 2). Similarly, the effects that relative-importance weights may have on the overall sensitivity index need to be considered, as such weights may emphasise/magnify a less sensitive environmental criterion and thus dilute highly sensitive factors. In order to address this, we recommend an evaluation of the effects that (changing) weights may have on the ESM outputs by re-running the model. Ultimately, this also enables exploration of varying stakeholder concerns. The various maps created can be saved, each print out map depicting the relative degree of environmental sensitivities within the plan/programme area, and including a list of the datasets selected (i.e. brought into the analysis) and their weights, which facilitates a contextualised interpretation of each mapped output (e.g. Fig. 6).

Although the creation of spatial data infrastructures across Europe has improved data discoverability and accessibility (González, 2012; Vanderhaegen and Muro, 2005), data availability limitations remain. This is particularly the case for certain SEA themes (e.g. landscape, soils) and for certain sectoral interventions (e.g. footprint of new housing or renewable energy developments). Such data limitations ultimately constrain localised assessments, as large scale detailed datasets are required to support local planning and EIA. As the ESM web tool is fully reliant on publicly available spatial datasets, currency, completeness and resolution remain issues. These deficiencies affect spatial assessment outputs (Cavan and Kingston, 2012; González, 2012). Ongoing maintenance of datasets included in the web tool, as these are updated or become available, is a pre-requisite for their effective and valid application (Ghaemi et al., 2009; González, 2017a). During the development of the ESM web tool, we gathered data manually by either downloading them from public sources or by submitting data requests. Some of the public data access websites have a web endpoint service that could facilitate updating data content; however, these are not consistently available across all sources. Moreover, the requirement for data pre-processing in order to provide SEA-specific indicators and content compelled the adoption of a download-and-save approach. The characteristics of the ESM datasets with regards to thematic areas, geographical scope and update timeframes enabled this ad-hoc approach, as a periodic review of the web tool coupled with the automated data processing models developed facilitate prompt maintenance. Nevertheless, necessary arrangements need to be put in place to avoid compromising the long-term availability and applicability of this SEA support tool as a result of a lack of specific data maintenance responsibilities and financial support. This will entail a commitment to make human and financial resources available beyond project completion; it has been estimated that quarterly data updates and ongoing general maintenance can be covered by approximately 5 person months.

The web tool focuses on the starting-point (i.e. intrinsic sensitivity of the receiving environment), leaving plenty scope to advance it and 
develop a more comprehensive SDSS that adopts a system-approach when examining sensitivity and impact significance (Aretano et al., 2015) and that is applicable across SEA of sectoral plans and programmes. This would also require the incorporation of flexibility in assessment detail, enabling the creation of mapping outputs at higher resolution (e.g. $20 \mathrm{~m}$ squared) to facilitate local level assessments and perhaps expand the applicability of the ESM widget to EIA. Nevertheless, these developments would require larger volumes of detailed data (e.g. high resolution qualifying features for the protection of biodiversity or anthropogenic interventions and activities, for example, which are currently unavailable or inaccessible in Ireland). They would entail more complex interactions and workflows affecting sciencepractice communication, understandability and, ultimately perhaps, credibility (Cartwright et al., 2016; Van Voorn et al., 2016; Wieland and Gutzler, 2014). In addition, they would demand higher server capacity and would, potentially, increase the complexity and user input requirements of the GUI. Nevertheless, the rapid advancement of technology and the growing move towards online data processing platforms provide significant yet untapped opportunities to break down access to data and specific technical expertise barriers. Arguably, such opportunities are further facilitated by the growing release of free and open source software and client-side web applications (Swain et al., 2016; Voinov et al., 2016; Walker and Chapra, 2014). Ultimately, technological innovation has the increasing potential to contribute to systematically and effectively examining human-environment interactions and to continue advancing SEA practice.

\section{Conclusion}

The ESM web tool provides online and user-friendly access to a full suite of basic GIS mapping tools and utilities, as well as a specialised environmental sensitivity analysis application (i.e. ESM widget). These tools facilitate the viewing, querying and analysis of SEA-relevant datasets. More importantly, the widget provides a quick and easy to apply method to consistently examine the potential for land-use conflicts in order to better inform planning decisions. The adoption of this online SEA support tool has the potential to improve the transparency and objectivity of assessments. Further live piloting the ESM web tool is needed to test the performance of the geoprocessing capabilities of the widget (including server performance in concurrent multiple-user scenarios), and to further review the coverage of available datasets and the existing functionality within the web tool. It has already been identified that to enhance the applicability of the web tool across planning hierarchies and sectors, additional sector-specific datasets (e.g. regulatory distances from housing for wind energy planning or soil productive capacity for agriculture) would need to be incorporated as these become available. There is also the possibility to augment the resolution of the analysis in order to provide finer detail for local level assessments. In addition, opportunities exist to expand its functionality by simply adding new tools that facilitate further interaction (e.g. functionality to download the raster outputs of the analysis) or by incorporating new geoprocessing widgets (and relevant data) that enable end-point analysis of sensitivity or, ideally, a comprehensive account of system's interactions.

The ESM web tool currently contains datasets specific to the Irish planning context, yet the spatial data management and processing workflow presented in this paper is readily reproducible and the approach transferable to other European and international SEA and EIA contexts. It therefore provides a basis for future developments in web based modelling and decision-making supports tools that are to comply with mandatory environmental assessment requirements. In this context, it is important to: a) provide a clear structuring of data and information that links to legislative understandings; b) include datasets that ensure a robust evidence-base and that enable systematic and replicable assessments at national level; c) deliver intuitive and interactive applications that facilitate participatory planning; and d) capture all model inputs into the final mapped output in order to ensure transparency in decision-making.

Despite recent developments in client-side solutions, web-mapping libraries remain limited and full interface customisation is often not possible with 'out of the box' commercial software applications. Specific programming code is still required for developing bespoke solutions. Nonetheless, online geoprocessing advancements have the potential to promote the seamless adoption of spatial approaches that promote participation and contribute to consistency and transparency in environmental assessment practice. This would not only enhance sciencepractice communication but also support more objective and accountable evidence-based decisions.

\section{Acknowledgments}

This work was supported by the Irish Environmental Protection Agency, under grant number 2013-B-FS-4. The authors are grateful to the project Steering Committee and to all the consulted stakeholders for participating in the project and for their insightful feedback. Thanks to Dr Anna Rymszewicz and Dr Christina Kelly for the contribution to data gathering and preparation. Thanks are also extended to the journal editor and to the reviewers for their constructive comments and useful input.

\section{References}

Adger, W.N., 2006. Vulnerability. Global Environ. Change 16 (3), 268-281. https://doi. org/10.1016/j.gloenvcha.2006.02.006

Antunes, P., Santos, R., Jordão, L., 2001. The application of geographical information systems to determine environmental impact significance. Environ. Impact Assess. Rev. 21, 511-535. https://doi.org/10.1016/S0195-9255(01)00090-7.

Aretano, R., Semeraro, T., Petrosillo, I., De Marco, A., Pasimeni, M.R., Zurlini, G., 2015 Mapping ecological vulnerability to fire for effective conservation management of natural protected areas. Ecological Modelling 295, 163-175. https://doi.org/10. 1016/j.ecolmodel.2014.09.017.

Aschemann, R., 2004. Lessons learned from austrian SEAs. European Environment 14 (3), 165-174. https://doi.org/10.1002/eet.347.

Atkinson, S.K., Canter, L.W., 2011. Assessing the cumulative effects of projects using Geographic Information Systems. Environmental Impact Assessment Review 31, 457-464. https://doi.org/10.1016/j.eiar.2011.01.008.

Babbar-Sebens, M., Mukhopadhyay, S., Singh, V.B., Piemonti, A.D., 2015. A web-based software tool for participatory optimization of conservation practices in watersheds. Environmental Modelling \& Software 69, 111-127. https://doi.org/10.1016/j. envsoft.2015.03.011.

Batty, M., 2013. Defining geodesign (= GIS + design?). Environment and Planning B 40, 1-2. https://doi.org/10.1068/b4001ed.

Boggia, A., Masseia, G., Paceb, E., Rocchia, L., Paolottia, L., Attard, M., 2018. Spatial multicriteria analysis for sustainability assessment: a new model for decision making. Landuse Policy 71, 281-292. https://doi.org/10.1016/j.landusepol.2017.11.036.

Cartwright, S.J., Bowgen, K.M., Collop, C., Hyder, K., Nabe-Nielsen, J., Stafford, R., Stillman, R.A., Thorpe, R.B., Sibly, R.M., 2016. Communicating complex ecological models to non-scientist end users. Ecological Modelling 338, 51-59. https://doi.org/ 10.1016/j.ecolmodel.2016.07.012.

Cavan, G., Kingston, R., 2012. Development of a climate change risk and vulnerability assessment tool for urban areas. International Journal of Disaster Resilience of the Built Environment 3 (3), 253-269. https://doi.org/10.1108/17595901211263648.

Dalal-Clayton, B., Sadler, D.B., 2005. Strategic Environmental Assessment: a Sourcebook and Reference Guide to International Experience. Earthscan, London ISBN: 1-84407179-0.

EC, 2001. Directive 2001/42/EC, of 27th June, on the assessment of the effects of certain plans and programmes on the environment. European commission. Official Journal of the European Union L197/30. 21.7.2001.

EC, 2003. Directive 2003/35/EC of the European Parliament and of the Council of 26 May 2003 providing for public participation in respect of the drawing up of certain plans and programmes relating to the environment and amending with regard to public participation and access to justice Council Directives 85/337/EEC and 96/61/ EC. European Communities. Official Journal of the European Union L156/17, 25/06/ 2003.

EC, 2014. Directive 2014/52/EU of the European parliament and of the council, of 16 April 2014, amending Directive 2011/92/EU on the assessment of the effects of certain public and private projects on the environment. European commission. Official Journal of the European Union L124/1. 25.4.2014.

Geneletti, D., Bagli, S., Napolitano, P., Pistocchi, A., 2007. Spatial decision support for strategic environmental assessment of land-use plans. A case study in southern Italy. Environmental Impact Assessment Review 27, 408-423. https://doi.org/10.1016/j. eiar.2007.02.005.

Ghaemi, P., Swift, J., Sister, C., Wilson, J.P., Wolch, J., 2009. Design and implementation of a web-based platform to support interactive environmental planning. Computers, 
Environment and Urban Systems 33, 482-491. https://doi.org/10.1016/j. compenvurbsys.2009.05.002.

González, A., 2012. GIS in environmental assessment: a review of current issues and future needs. Journal of Environmental Assessment Policy and Management 14, 23. https://doi.org/10.1142/S146433321250007X. 1250007.

González, A., 2017a. Mapping environmental sensitivity: a systematic online approach to support environmental assessment and planning. Environmental Impact Assessment Review 66, 86-98. https://doi.org/10.1016/j.eiar.2017.06.010.

González, A., 2017b. A conceptualisation framework for building consensus on en vironmental sensitivity. Journal of Environmental Management 200, 114-122. https://doi.org/10.1016/j.jenvman.2017.05.061.

González, A., Gazzola, P., 2011. The ICT-based face of public organizations. In: Sarlak, M. (Ed.), The New Faces of Organizations in the 21st Century. NAISIT Publishers, Canada, pp. 56-89 ISBN 978-0986533501.

González, A., Gilmer, A., Foley, R., Sweeney, J., Fry, J., 2011. Applying geographic information systems to support strategic environmental assessment: opportunities and limitations in the context of Irish land-use plans. Environmental Impact Assessment Review 31 (3), 368-381. https://doi.org/10.1016/j.eiar.2010.12.001.

Jay, S., Jones, C., Slinn, P., Wood, C., 2007. Environmental impact assessment: retrospect and prospect. Environmental Impact Assessment Review 27 (4), 287-300. https:// doi.org/10.1016/j.eiar.2006.12.001.

Jetz, W., McPherson, J.M., Guralnick, R.P., 2012. Integrating biodiversity distribution knowledge: toward a global map of life. Trends in Ecology and Evolution 27 (3), 151-159. https://doi.org/10.1016/j.tree.2011.09.007.

Jones, C., Baker, M., Carter, J., Jay, S., Short, M., Wood, C., 2005. Evaluating the SEA of land-use plans. In: Jones, C., Baker, M., Carter, J., Jay, S., Short, M., Wood, C. (Eds.), Strategic Environmental Assessment and Land-use Planning - an International Evaluation. Earthscan, London, pp. 28-43.

Kitchin, R., 2014. The Data Revolution: Big Data, Open Data, Data Infrastructures and Their Consequences. SAGE Publications Ltd., London ISBN: 978-1446287477.

Kværner, J., Swensen, G., Erikstad, L., 2006. Assessing environmental vulnerability in EIA - the content and context of the vulnerability concept in an alternative approach to standard EIA procedure. Environmental Impact Assessment Review 26, 511-527. https://doi.org/10.1016/j.eiar.2006.01.003.

Labiosa, W.B., Forney, W.M., Esnard, A.M., Mitsova-Boneva, D., Bernknopf, R., Hearn, P., Hogan, D., Pearlstine, L., Strong, D., Gladwin, H., Swain, E., 2013. An integrated multi-criteria scenario evaluation web tool for participatory land-use planning in urbanized areas: the Ecosystem Portfolio Model. Environmental Modelling \& Software 41, 210-222. https://doi.org/10.1016/j.envsoft.2012.10.012.

Malczewski, J., 1999. GIS and and Multicriteria Decision Analysis. John Wiley \& Sons, New York ISBN: 9780471329442.

Malczewski, J., 2002. Fuzzy screening for land suitability analysis. Geographical and Environmental Modelling 6 (1), 27-39. https://doi.org/10.1080/ 13615930220127279.

Marull, J., Pino, J., Mallarach, J.M., Cordobilla, M.J., 2007. A land suitability index for Strategic Environmental Assessment in metropolitan areas. Landscape and Urban Planning 81, 200-212. https://doi.org/10.1016/j.landurbplan.2006.11.005.

Michielsen, A., Kalantari, Z., Lyon, S.W., Liljegren, E., 2016. Predicting and communicating flood risk of transport infrastructure based on watershed characteristics. Journal of Environmental Management 182, 505-518. https://doi.org/10.1016/j jenvman.2016.07.051.

Mourhir, A., Rachidi, T., Papageorgiou, E.I., Karim, M., Alaoui, F.S., 2016. A cognitive map framework to support integrated environmental assessment. Environmental Modelling \& Software 77, 81-94. https://doi.org/10.1016/j.envsoft.2015.11.018.

Munda, G., 2004. Social multi-criteria evaluation: methodological foundations and operational consequences. European Journal of Operational Research 158, 662-677. https://doi.org/10.1016/S0377-2217(03)00369-2.

Rao, M., Fang, G., Thomas, J., Cherian, G., Chudiwale, V., Awawdeh, M., 2007. A webbased GIS decision support system for managing and planning USDA's conservation reserve program (CRP). Environmental Modelling \& Software 22, 1270-1280. https://doi.org/10.1016/j.envsoft.2006.08.003.

Riddlesden, D., Singleton, A.D., Fischer, T.B., 2012. A survey of the use of geographic information systems in English local authority impact assessments. Journal of Environmental Assessment Policy and Management 14, 14. https://doi.org/10.1142/ S1464333212500068. 1250006.

Runhaar, H., Driessen, P.P.J., 2007. What makes strategic environmental assessment successful environmental assessment? The role of context in the contribution of SEA to decision-making. Impact Assessment and Project Appraisal 25 (1), 2-14. https:// doi.org/10.3152/146155107X190613.

Simão, A., Densham, P.J., Haklay, M.M., 2009. Web-based GIS for collaborative planning and public participation: an application to the strategic planning of wind farm sites. Journal of Environmental Management 90 (6), 2027-2040. https://doi.org/10.1016/ j.jenvman.2007.08.032.

Sizo, A., Noble, A., Bell, S., 2016. Strategic Environmental Assessment framework for landscape-based, temporal analysis of wetland change in urban environments. Environmental Management 57, 696-710. https://doi.org/10.1007/s00267-0150640-8.

Smith, D.A., 2016. Online interactive thematic mapping: applications and techniques for socio-economic research. Computers, Environment and Urban Systems 57, 106-117. https://doi.org/10.1016/j.compenvurbsys.2016.01.002.

Sugumaran, R., Meyer, J.C., Davis, J., 2004. A Web-based environmental decision support system (WEDSS) for environmental planning and watershed management. Journal of Geographical Systems 6, 307-322. https://doi.org/10.1007/s10109-004-0137-0.

Swain, N.R., Christensen, S.D., Snow, A.D., Dolder, H., Espinoza-Dávalos, G., Goharian, E., Jones, N.L., Nelson, E.J., Ames, D.P., Burian, S.J., 2016. A new open source platform for lowering the barrier for environmental web app development. Environmental Modelling \& Software 85, 11-26. https://doi.org/10.1016/j.envsoft. 2016.08.003.

Therivel, R., 2004. Strategic Environmental Assessment in Action. Earthscan, London ISBN: 978-1849710657.

Vanderhaegen, M., Muro, E., 2005. Contribution of a European spatial data infrastructure to the effectiveness of EIA and SEA studies. Environmental Impact Assessment Review 25 (2), 123-142. https://doi.org/10.1016/j.eiar.2004.06.011.

Van Voorn, G.A.K., Verburg, R.W., Kunseler, E.M., Vader, J., Janssen, P.H.M., 2016. A checklist for model credibility, salience, and legitimacy to improve information transfer in environmental policy assessments. Environmental Modelling \& Software 83, 224-236. https://doi.org/10.1016/j.envsoft.2016.06.003.

Vicente, G., Partidário, M.R., 2006. SEA - enhancing communication for better environmental decisions. Environmental Impact Assessment Review 26, 696-706. https://doi.org/10.1016/j.eiar.2006.06.005.

Voinov, A., Kolagani, N., McCall, M.K., Glynn, P.D., Kragt, M.E., Ostermann, F.O., Pierce, S.A., Ramu, P., 2016. Modelling with stakeholders - next generation. Environmental Modelling \& Software 77, 196-220. https://doi.org/10.1016/j.envsoft.2015.11.016.

Walker, J.D., Chapra, S.C., 2014. A client-side web application for interactive environmental simulation modelling. Environmental Modelling \& Software 55, 49-60. https://doi.org/10.1016/j.envsoft.2014.01.023.

Wang, X.D., Zhong, X.H., Liu, S.Z., Liu, J.G., Wan, Z.Y., Li, M.H., 2008. Regional assessment of environmental vulnerability in the Tibetan Plateau: development and application of a new method. Journal of Arid Environments 72, 1929-1939. https:// doi.org/10.1016/j.jaridenv.2008.06.005.

Wieland, R., Gutzler, C., 2014. Environmental impact assessment based on dynamic fuzzy simulation. Environmental Modelling \& Software 55, 235-241. https://doi.org/10. 1016/j.envsoft.2014.02.001.

Wood, C., 2013. Environmental Impact Assessment: a Comparative Review. Routledge, London: UK ISBN: 978-0-582-36969-6.

Yoo, G., Kim, R.A., Hadi, S., 2014. A methodology to assess environmental vulnerability in a coastal city: application to Jakarta, Indonesia. Ocean Coastal Management 102 (A), 169-177. https://doi.org/10.1016/j.ocecoaman.2014.09.018. 